\title{
A Educação e a Justiça Social na Superação das Desigualdades Sociais
}

\section{Education and Social Justice in Overcoming Social Inequalities}

\section{Educación y Justicia Social en Superar Desigualdades Sociales}

\footnotetext{
(iD) Michelle Popenga Geraim Monteiro Universidade Federal do Paraná

iD (9) Tatiane Delurdes de Lima-Berton ${ }^{1}$ Universidade Federal do Paraná

Alessandra de Paula Pereira Universidade Federal do Paraná

Araci Asinelli-Luz

Universidade Federal do Paraná
}

Resumo: Para expressar o reconhecimento da importância da Educação no processo de superação de violências e na prevenção do abuso de drogas, este artigo apresenta uma pesquisa de cunho qualitativo, advindo de um Curso de Extensão "A prevenção como princípio para o enfrentamento do abuso de drogas", da Universidade Federal do Paraná, no segundo semestre/2016. Tem como metodologia, a coleta de dados por meio das palavras evocadas e, como análise dos dados, as expressões que foram mais eviden-

1. "O presente trabalho foi realizado com apoio da Coordenação de Aperfeiçoamento de Pessoal de Nível Superior - Brasil (CAPES) - Código de Financiamento 001". 
tes. Para a discussão, no contexto social e educacional, amplia-se o olhar para o âmbito da Educação Preventiva Integral, ligando-a a educação transformadora na perspectiva de Paulo Freire (1987; 1997; 2000). Acredita-se que pensar por esta ótica aumenta-se a chance concreta de uma realidade educativa melhor por meio de uma educação transformadora, implicando em ações preventivas, em favor, além da prevenção do abuso de drogas, da compreensão do ser humano e da minimização das desigualdades e vulnerabilidades sociais, em especial aquelas ligadas ao âmbito escolar, à infância e a adolescência.

Palavras-chave: Educação Preventiva Integral. Educação transformadora. Extensão Universitária. Pedagogia Social. Vulnerabilidades.

Abstract: To express the recognition of the importance of Education in the process of overcoming violence and in the prevention of drug abuse, this article presents a qualitative research, coming from an Extension Course "Prevention as a principle for coping with drug abuse", from Federal University of Paraná, in the second semester of 2016. Its methodology is the collection of data through the evoked words and, as data analysis, the expressions that were most evident. For the discussion, in the social and educational context, the perspective of Integral Preventive Education is broadened, linking it to transformative education in the perspective of Paulo Freire (1987; 1997; 2000). It is believed that thinking from this perspective increases the concrete chance of a better educational reality through a transformative education, implying preventive actions in favor, in addition to the prevention of drug abuse, human understanding and minimization of social inequalities and vulnerabilities, especially those related to school, childhood and adolescence.

Keywords: Integral Preventive Education. Social pedagogy. Transformative education. University Extension. Vulnerability. 
Resumen: Para expresar el reconocimiento de la importancia de la educación en el proceso de superación de la violencia y en la prevención del abuso de drogas, este artículo presenta una investigación cualitativa, proveniente de un curso de extensión "La prevención como principio para hacer frente al abuso de drogas", de la Universidad Federal de Paraná, en el segundo semestre de 2016. Su metodología es la recopilación de datos a través de las palabras evocadas y, como análisis de datos, las expresiones más evidentes. Para la discusión, en el contexto social y educativo, se amplía la perspectiva de la Educación Preventiva Integral, vinculándola con la educación transformadora en la perspectiva de Paulo Freire (1987; 1997; 2000). Se cree que pensar desde esta perspectiva aumenta las posibilidades concretas de una mejor realidad educativa a través de una educación transformadora, lo que implica acciones preventivas a favor, además de la prevención del abuso de drogas, la comprensión humana y la minimización de desigualdades y vulnerabilidades sociales, especialmente las relacionadas con la escuela, la infancia y la adolescencia.

Palabras clave: Educación Preventiva Integral. Educación transformadora. Extensión Universitaria. Pedagogía social. Vulnerabilidades. 


\section{Introdução}

Todo ser humano pode ser considerado frágil e vulnerável diante das situações em que são inexistentes ou insuficientes os recursos para o enfrentamento dos obstáculos que são apresentados em seu caminho e que ameaçam a sua suficiência enquanto ser independente. A vulnerabilidade, compondo-se de limitações, fragilidades e dependências, ocorrem de maneira indissociável às esferas humanas caracterizadas pela biológica, psicológica e social, em que o sujeito não possui, muitas vezes, a consciência da gravidade dos fatos (ROMERO, 2009).

As crianças, devido ao seu intenso processo de desenvolvimento, são consideradas ainda mais vulneráveis. Desde o dia do seu nascimento é cercada por tensões em todos os âmbitos e a ideia de fragilidade e dependência de um ser humano adulto elevam as situações de submissão ao ambiente físico e social. Dentre os seres vivos, o ser humano possui um longo período de dependência de seu responsável, sendo elas física, psicológica, emocional, afetiva, financeira e social (ABRAMOVAY; LIMA; VARELLA, 2003; ROMERO, 2009; MONTEIRO, 2017b).

No Brasil, existem desigualdades em diversos setores sociais, que se manifestam por meio da situação de vida das pessoas que vivem no país, em especial àquelas que se encontram socialmente desprovidas, vindo a aumentar o contexto de vulnerabilidade. Por isso, há consenso entre a maioria que se sente oprimida por um movimento que evoque a justiça e a equidade social, pois estas lutam por melhorias sociais como a justa distribuição de oportunidades e recursos que ainda se encontram na mão de alguns privilegiados, com a intenção de equalizar a população (BORGES, 2015).

Considerando os desdobramentos que a vulnerabilidade e as desigualdades englobam, no que diz respeito ao sentido de violên- 
cia presente, observa-se que o conceito é amplo e atinge o ser humano de diversas formas. Muitas são as violências, que implicam em diferentes atores e formas de experiências e vivências. Por isso, conceituar violência, na dimensão da vulnerabilidade e da desigualdade, vai muito além de apenas definir como uma forma de agressividade contra o outro, mas mostra a multidimensionalidade e a complexidade deste conceito. Destacam-se, nesse sentido, as inúmeras violações de direitos por que passam, em especial, a infância e a adolescência. Assim, práticas sociais e institucionais e/ ou econômicas e políticas que limitam o ser humano de alguma forma podem ser consideradas como formas de violência: a pobreza, a miséria, condições precárias de vida, entre outros (MONTEIRO, 2017b).

Posto isto, a violência em contexto escolar, relacionada às vulnerabilidades e desigualdades sociais, tem ganhado relevância e tornou-se um tema cotidiano atualmente. É considerada como um problema social que precisa de intervenção e de uma visão crítica que abarque mecanismos que auxilie em sua minimização no contexto escolar. Assim, evidencia-se a complexidade da temática, exigindo um diálogo intersetorial e a aproximação entre a educação e a justiça social. As formas de violência urbana são promovidas pela ordem social em confronto aos grupos socialmente desfavorecidos. Isso acaba acarretando efeitos psicológicos e relacionais frente ao terror urbano: medo de ser violentado (a), descrédito das autoridades (agentes perdem a legitimidade), desconfiança nos princípios que asseguram a ordem social (validade e legitimidade dos poderes públicos), enfraquecimento dos valores de coletivo/solidariedade/justiça/direito (ROMERO, 2009).

Os desentendimentos e violência doméstica reforçam as psicopatias do cotidiano devido, ao evidenciar conflitos entre casal, conflitos derivados de dissolução familiar e divórcio, bem como a desintegração do grupo e a indigência econômica. Em relação aos 
efeitos nocivos do sistema social, há a problemática de privatização de espaços públicos, em que o Estado demonstra a incapacidade ao garantir a paz social. Na questão da exploração do trabaIho, existe o despreparo educacional e profissional, mecanização de relações e ações, exploração infantil e do imigrante, bem como conflitos entre papéis e abuso de poder. Sobre a diminuição da qualidade de vida pela degradação do meio ambiente, é destacado o excesso de poluição, a ausência de saneamento básico e a precariedade do serviço público (ROMERO, 2009).

Diante de tantas formas de violência e de situações de risco e vulnerabilidade social, o conceito de violência que envolve crianças e adolescentes não é observado como uma manifestação recente. Ele perpassa por várias raízes culturais e históricas e mesmo assim, não se pode admitir a sua aceitação como parte da condição humana, como algo naturalizado e inato. Por isso, muitos são os sistemas desenvolvidos para evitar e minimizar as violências na sociedade (MONTEIRO, 2017b).

É importante reconhecer também que existem leis que priorizam a proteção integral da criança e do adolescente (Estatuto da Criança e do Adolescente - ECA), mas que ainda faltam recursos e o cumprimento efetivo destas em favor dos mesmos, em especial as que vivem em situações de risco e de vulnerabilidades sociais. A sensibilização em relação a este cumprimento ainda é frágil o que torna difícil o convencimento por parte da população e das políticas governamentais da importância do ECA. Dessa forma, as crianças ainda vivem em situações inadequadas e precárias, tendo seus direitos violados por todo tipo de violência.

Diante disso, acredita-se que a chave para a superação das mazelas sociais é a educação transformadora, que privilegia a justiça social como ponto de partida. Um dos autores que auxilia no processo de compreensão da importância da educação vincula- 
da a justiça social, com foco na transformação do sujeito é Paulo Freire, que traz sua Pedagogia crítico-libertadora. Os desafios de superação das desigualdades e na minimização das fragilidades e vulnerabilidades humanas que se encontram tão alargadas na sociedade estão vinculados à educação, compreendida como um meio de transformação social e com a busca do aperfeiçoamento do indivíduo, tendo em vista o seu o inacabamento.

Essas considerações conduzem o presente estudo para a seguinte pergunta norteadora: de que maneira a educação pode trazer justiça social para os sujeitos que se encontram em situações de vulnerabilidades e desigualdades sociais? Como a educação pode ajudar na prevenção do abuso de drogas? Para expressar como a Educação é importante para superação das desigualdades e vulnerabilidades sociais, apresenta-se neste estudo uma pesquisa em um Curso de Extensão Universitária sobre prevenção do abuso de drogas, da Universidade Federal do Paraná, na qual estudantes de diferentes áreas levantaram a importância da Família, da Educação, do conhecimento e da Humanização para a superação dessa violência que acomete crianças e adolescentes.

Portanto, o artigo compõe-se de um estudo que abrange a educação e a justiça social como formas de superação das desigualdades sociais e, consequentemente, na minimização das vulnerabilidades. Trata-se de um estudo qualitativo e teórico, na perspectiva freiriana. Seu objetivo geral é valorizar a educação como alicerce para a justiça social na superação das desigualdades e vulnerabilidades sociais. Nesse âmbito, a relevância do estudo na área educacional justifica-se em razão da produção de conhecimento no campo teórico-metodológico para a comunidade escolar, como forma de reflexão sobre as relações sociais, além de tornar-se um meio de suscitar discussões entre sociedade acadêmica e demais agentes inseridos no campo da educação. 


\section{Encaminhamentos Metodológicos}

Para ilustrar o reconhecimento da Educação enquanto alicerce para superação de violências e desigualdades sociais promoveu-se a análise de fichas com palavras evocadas de estudantes de um Curso de Extensão Universitária, oferecido pela Universidade Federal do Paraná, intitulado "A prevenção como princípio para o enfrentamento do abuso de drogas". Em conjunto da Disciplina Eletiva de Métodos e Técnicas de Prevenção do abuso de drogas (EM 377), é a única disciplina em currículo de graduação ofertada por uma Universidade com a temática de prevenção ao abuso de drogas.

A coleta de dados consiste na apresentação de palavras evocadas: no primeiro dia de aula, os estudantes eram convidados a preencherem uma ficha com palavras evocadas, onde eles elencaram as quatro primeiras palavras que surgiam à mente quando pensavam em prevenção do abuso de drogas. Após as palavras, colocava-se a justificativa para elas.

Para a análise de dados, das palavras evocadas, buscaram-se as expressões que foram mais evidentes, para exposição e reforço do tema apresentado. Para a discussão dos resultados, destaca-se o âmbito da Educação Preventiva Integral, ligando-a a educação transformadora na perspectiva de Paulo Freire (1987; 1997; 2000).

Em relação aos participantes, a Disciplina Eletiva e o Curso de Extensão abrangiam 55 estudantes. Destes, 23 eram da comunidade, ou seja, da modalidade de Curso de Extensão. Dos 23, 19 possuíam graduação (História, Psicologia, Pedagogia, Ciências Biológicas, Enfermagem, Jornalismo e Serviço Social) e 4 da modalidade do Ensino Médio. Em relação ao gênero, são 05 masculinos e 18 femininos. 


\section{Análise e Discussão dos Resultados}

Realizando a análise das palavras evocadas, percebeu-se que as palavras que emergiram em cada um dos 04 grupos. Na primeira preferência dos estudantes, a palavra que mais apareceu foi família. A segunda preferência expressou educação, a terceira preferência emergiu conhecimento e a quarta preferência humanização. Porém, quando se menciona essas palavras no total das quatro preferências, a ordem em que elas aparecem por mais repetições são: educação (7), conhecimento (6), família (4) e humanização (4).

Em relação à família, destaca-se que as vulnerabilidades mais comuns que estão presentes na vida e no desenvolvimento infantil são, em geral, aquelas relacionadas a conflitos e violência familiar, bem como situações no âmbito social decorrente da cultura das desigualdades, fator predominante no país. Condição de moradia, oferta dos serviços públicos, relações sociais violentas e de risco como o envolvimento com drogas, trabalho infantil e exploração sexual também as afetam e as tornam mais vulneráveis. Então, as vulnerabilidades são manifestadas por meio de consequências na vida das crianças, em seus contextos de maior vivência: a família e a escola (ABRAMOVAY; LIMA; VARELLA, 2003; ROMERO, 2009; SALLES FILHO, 2016).

No contexto da coletividade, dos espaços de interação, reforça-se o papel da família, da escola e de outros espaços educativos como influenciadores no desenvolvimento humano e no processo das relações sociais. Depois da família, a instituição escolar é o segundo ambiente de maior contato, garantido por lei, responsável pela transmissão dos conteúdos historicamente acumulados, mas também encarregada por boa parte da mediação entre pares e entre os valores construídos na sociedade. Como expressado nas palavras evocadas dos participantes, as palavras educação, 
conhecimento e humanização reforçam que o caminho do ensino é a formação cidadã e humanizadora, construção da autonomia e pertença ao grupo social. Paulo Freire relacionava, neste sentido, a educação transformadora à capacidade do ser humano em indagar as injustiças sociais que permeiam o contexto no qual se está inserido, por meio do processo de conscientização que somente acontece pelo ato de educar, conduzindo o sujeito ao engajamento na transformação social (BORGES, 2015; BENATTO, 2016; FREI$R E$, 1987).

A educação não se restringe a conceitos científicos e técnicos, pois, vai muito além dessas considerações. Quem está nessa área, precisa obter a clareza de que se relacionando com pessoas, o trabalho será muito mais complexo, em que não estará atuando com máquinas e sim, com seres pensantes e ativos. Assim, além da formação técnica, exigirá um envolvimento comprometido e afetivo, onde o educador precisará estar disposto a lidar com o desconhecido. Tratando-se de seres humanos, todos são capazes de discutir, refletir, produzir novos valores, habilidades, sabendo das diferenças, necessidades e das formas diversas de caminhar ao crescimento do grupo social. O processo de formação humana envolve a educação que ocorre "na vida familiar, na convivência humana, no trabalho, nas instituições de ensino e pesquisa, nos movimentos sociais e organizações da sociedade civil e nas manifestações culturais". (BRASIL, 1996, p. 01).

Com o passar do tempo, a sociedade foi adquirindo novos hábitos, culturas e valores em todas as classes populacionais existentes e para que se conseguisse abranger essa demanda, fez-se necessário abrir espaços para a promoção da cidadania e da interação social. Na compreensão de que não há apenas um único espaço de promoção de ações educativas, há além da educação escolar, a não escolar, envolvendo práticas que visam a superação 
das vulnerabilidades e riscos sociais, bem como do estímulo à autonomia, paz, igualdade, justiça social e a criação e fortalecimento de vínculos afetivos.

A Pedagogia Social, como área de conhecimento, auxilia no processo formativo visando a compreensão do sujeito e de suas relações, muito além da função escolar. Nesse aspecto, há a área da Educação Social, com a atuação do educador social (profissional que poderá atuar em diferentes espaços - escolares e não escolares). Segundo Souza e Müller (2009) a nomenclatura Educação Social vem, ao longo do tempo, se concentrando na forma de educação não escolar, voltada à garantia de direitos humanos e formação de indivíduos políticos, diferenciada do ensino formal de escolarização.

Salienta-se a necessidade de reorganizar as ações para o atendimento às demandas do quadro social existente, visto que o ambiente educacional - escolar e não escolar - apresentam meios de interação e possibilidade de solução de conflitos, que apresentam a relevância de qualificação para o educador social. Para isso, a formação inicial e continuada na área da Educação Social e da Pedagogia Escolar/Social tornam-se fundamentais para a descoberta, construção e reconstrução de saberes, promovendo análises e possibilidades de protagonismo e interação social (LIMA, 2017a, p. 70).

Com a educação, nos espaços escolares e não escolares, há a oportunidade de estimular a interação social, o diálogo, a reflexão sobre demandas individuais e coletivas, na intenção da superação de vulnerabilidades e riscos sociais. É um andar coletivo, de antecipar que problemas ocorram, de prevenir violências e injustiças sociais. A educação, nesse âmbito, torna-se uma ferramenta 
social para superar qualquer tipo de preconceito ou demanda advinda da coletividade.

No entendimento da importância da educação transformadora para superação das desigualdades e vulnerabilidades sociais, faz-se necessário compreender que a vulnerabilidade possui uma origem profunda, enraizada na estrutura humana, e para a sua superação, há a necessidade de criar condições de existência e linhas de desenvolvimento voltadas ao sujeito. Não é preciso eliminar o sistema capitalista, mas, minimizar suas expressões, a fim de superar quatro fatores: a desigualdade da distribuição da riqueza; que a democracia deixe de ser utilizada apenas para efeitos eleitoreiros para que se efetive (ampliar seu conceito para a convivência em sociedade); modificar o papel da mídia, meio de modelagem da consciência coletiva e, oportunizar uma educação que deixe de ser memorística e mecânica e que realmente se torne potencializadora da consciência e criticidade humana (ROMERO, 2009).

Além das consequências ocasionadas pela desigualdade, o capitalismo tornou-se uma arma que derrota a solidariedade e a partilha, pois provoca muita disputa entre as pessoas. A tecnologia suscita a mesma problemática, em que acaba acarretando a alienação. Para tentar preservar a diferença e diminuir os problemas voltados ao capitalismo e a tecnologia, acredita-se que seja fundamental reforçar a ética, os valores e o respeito ao próximo, componentes obrigatórios dos processos e contextos educacionais. As pessoas precisam voltar a se tornar humanas, de viver em harmonia e em coletividade - resgatar a humanização. Sobre essa banalização e alienação coletivas mediante a tecnologia e o capitalismo, Romero (2009) destaca que os meios de comunicação são invenções extraordinárias para o mundo, que estimulam a diversão e a criatividade humana. Porém, por determinadas fontes, tornam-se massivas e manipuladoras, causando forte impacto para os fenô- 
menos sociais de maneira negativa. Podem influenciar a injustiça social, o sexismo, o fomento da idolatria, exaltação do grotesco e de valores de mercado/consumismo, promoção de superstições e condicionamento/programação da mente coletiva.

\section{Educação, Justiça Social e a Superação das Desigualdades}

O termo vulnerabilidade foi considerado uma predisposição do surgimento de psicopatologias e/ou comportamentos em situação de crise. Entre 1970 e 1980, pesquisadores ingleses e norte-americanos notaram que alguns grupos de pessoas pareciam não se abater com problemáticas, sendo considerados como invulnerabilidade (resistência ao estresse/resiliência). Até meados da década de 90, a análise do conceito de vulnerabilidade social era relacionado predominantemente à economia, considerando a pobreza como fator que reduziria o acesso e as oportunidades as pessoas que viveram esta condição. ((BRANDÃO; MAHFOUD; GIANORDOLI-NASCIMENTO, 2009; ROMERO, 2009).

Com o avanço de pesquisas na área, o conceito de vulnerabilidade social ampliou-se, associando tal palavra à insegurança, sensibilidade a mudanças de ambiente e falta de resiliência aos riscos. Nos anos 2000, incorporado novos elementos ao conceito, em uma visão mais abrangente, entende-se que todos os seres humanos são vulneráveis e estão constantemente vivendo situações pelas quais podem estar em risco (ROMERO, 2009; BENATTO, 2016). “Compreende-se, portanto, a vulnerabilidade como uma conjunção de fatores, sobrepostos de diversas maneiras e em várias dimensões, de modo a tornar o indivíduo ou grupo mais suscetível aos riscos e contingências" (CANÇADO; SOUSA; CARDOSO, 
2014, p. 03). Assim, a vulnerabilidade social é um conceito complexo e pode estar associada a qualquer situação que afete o bem-estar humano.

\section{4}

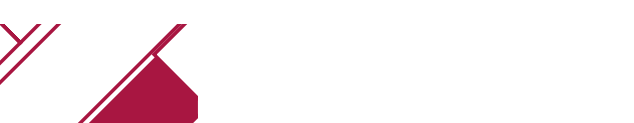

\begin{abstract}
As noções de "exclusão" e de "vulnerabilidade social" têm sido cada vez mais utilizadas, no Brasil e no mundo, por pesquisadores, gestores e operadores de políticas sociais, num esforço de ampliação do entendimento das situações tradicionalmente definidas como de pobreza, buscando exprimir uma perspectiva ampliada complementar àquela atrelada à questão da insuficiência de renda. Assim como as noções de "necessidades básicas insatisfeitas", "pobreza multidimensional” e "desenvolvimento humano", exclusão e vulnerabilidade social são noções antes de tudo, políticas (ainda que nem sempre sejam percebidas como tal), que introduzem novos recursos interpretativos sobre os processos de desenvolvimento social, para além de sua dimensão monetária (BRASIL, 2015, p. 12).
\end{abstract}

Neste sentido, a preocupação aumentou em torno da infância e da adolescência, pois a identificação de crianças e adolescentes que vivem em situações de vulnerabilidades sociais cresce cada vez mais. São aquelas que vivem as consequências das desigualdades sociais, como pobreza, exclusão social, falta de vínculos afetivos, falta de acesso à escola, lazer, saúde, falta de recursos, abuso de drogas, violência, entre outros. Posto isto, deve-se levar em conta que o trabalho com crianças e adolescentes em situações de vulnerabilidade e desigualdade social abarca diversas dimensões de desvantagem social, destacando-se os vínculos relacionais e emocionais que são fragilizados e difíceis de lidar, tornando-os passivos, comprometidos emocionalmente e dependentes. Assim, o ciclo continua se reforçando nas condições já existentes para este sujeito (BENATTO, 2016). 
Conhecimentos na área da infância, adolescência e juventude enriquecem cada vez mais as possibilidades de atuação e proteção aos direitos fundamentais desses sujeitos, percebendo a importância das ações contra qualquer manifestação de negligência, discriminação, exploração, violência, crueldade e opressão. Ampliar o olhar sobre os agentes de proteção (família, instituição escolar, Conselho Tutelar, instituições de acolhimento, serviços de convivência e fortalecimento de vínculos e demais órgãos públicos/privados) auxiliam para a construção da consciência da importância da Rede de Proteção, percebendo que mesmo havendo equipamentos que oportunizam e asseguram os direitos, também há os que são negligentes, nos possibilitando o monitoramento e o dever de cuidado de todos os cidadãos.

Desse modo, é necessário que ações preventivas sejam o ponto de partida para o desenvolvimento individual e coletivo, favorecendo a discussão e a reflexão sobre os aspectos que envolvem a consciência crítica sobre valores, diversidade e outras esferas da sociedade, antecipando a compreensão do sujeito e de suas problemáticas para o enfrentamento de dificuldades, bem como de investimento no coletivo por meio da cidadania, da igualdade e da justiça social. Prevenção esta no sentido de amparar o indivíduo dentro de sua história, contexto e necessidades, permitindo que se torne autor diante dos desafios e enfrentamentos cotidianos. A superação dos riscos, das desigualdades e vulnerabilidades sociais presentes na sociedade exige uma estrutura de conhecimentos amplos sobre os fatores relacionados à elas, como os econômicos, socioculturais, psicológicos, políticos e contextuais, com a intenção de promover mecanismos de ação coletiva para o enfrentamento das problemáticas (LIMA, 2017a). Freire (1987) ressalta a importância das relações estabelecidas entre os sujeitos como uma das for- 
mas de construção coletiva, que trazem criticidade, dialogicidade e potencial transformador.

\begin{abstract}
Desde logo, um dos primeiros cuidados dessa política de educação e de tudo o que ela arrasta consigo, é o de "recuperar" os pobres, os doentes, aqueles que não são privilegiados. Noutros termos, esta ideologia pensa mudar os homens sem mudar as estruturas sociais. Seria ingênuo esperar que as elites no poder procurassem desenvolver e prosseguir uma forma de educação que ajudasse as pessoas a defrontar os problemas sociais de modo crítico (FREIRE, 1997, p. 23).
\end{abstract}

Promover a justiça social, por meio da educação, é explicitar valores sociais, consiste em uma mudança de paradigmas e conceitos construídos socialmente, justamente porque a própria justiça social é um valor coletivo, que busca a distribuição justa de recursos entre os sujeitos. Portanto, significa que a educação, para vencer as mazelas sociais, tão arraigadas nos dias de hoje, precisa ir ao sentido contrário à visão de mundo e de valores que estão postos na sociedade. Está atrelada a uma mudança social (SILVA, SARRIERA, 2015).

Reafirma-se na educação a importância das reflexões éticas e críticas, a busca pelos direitos e o respeito entre os seres humanos e o anseio pela mudança, que transforma o eu para o coletivo, a partir de um olhar pedagógico humanizador de acordo com a realidade social. É uma visão esperançosa de um caminho para emancipar os oprimidos. Em um exemplo de superação às vulnerabilidades sociais, reforça-se o pensamento sobre a maneira de assimilar a constituição da democracia, pois, se o autoritarismo não abre espaço, não há como se desenvolver a liberdade. Assim, só haverá possibilidades à medida que a liberdade for construída 
A Educação e a Justiça Social na Superação das Desigualdades Sociais Michelle Popenga Geraim Monteiro - Tatiane Delurdes de Lima-Berton, et al...

ao lado da generosidade autêntica e da ética ao invés da obediência e do medo (FREIRE, 1987).

Faz-se conveniente abrir espaços de diálogo, interação e reflexão, a fim de encontrar uma solução ao problema, na perspectiva de prevenir as causas que o geram. Professores, educadores sociais, poderão desenvolver ações que visem o estímulo ao respeito à cultura de origem do sujeito, abrir espaço para que sejam compreendidos os seus desafios e suas habilidades, a maneira como podem descobrir caminhos para enfrentar as dificuldades e como participar ativamente na sociedade.

O processo formativo não deve ser organizado apenas pelos agentes educativos, sejam eles do espaço escolar e não escolar, mas também da mediação adulta no processo de transição de ideias, sentimentos e condutas, assim como a família e outros sujeitos que fazem parte do contexto, tais como igrejas ou outros locais de convivência e fortalecimento de vínculos. Adota-se, nesse meio, uma educação preventiva integral ${ }^{2}$, capaz de estimular o sujeito no processo de consciência de suas demandas/potencialidades, para então buscar superar uma dificuldade. É obter o foco no ser e não no seu conflito (ASINELLI-LUZ, 2014).

À medida que o sujeito se torna capaz de reinterpretar as informações que the são postas socialmente e analisar as situações que o desprotegem, há maiores chances de superação dos conflitos. Nesse âmbito, reafirma-se a necessidade da educação preventiva, de proporcionar a construção da consciência da importância do desenvolvimento humano.

O diálogo torna-se um fator fundamental para todo o processo. Na busca pela justiça social, pela sua compreensão dentro dos contextos da sociedade, se faz necessário refletir sobre as de-

2. Trata-se da promoção de uma educação preventiva, em que a relação entre os sujeitos proporcionará reflexões e ações voltadas ao desenvolvimento e relações humanas, considerando que este processo de prevenção antecipa os problemas por meio do crescimento e a valorização do ser, na busca pela promoção da garantia de direitos humanos fundamentais e justiça social. 
mandas e potencialidades de cada sujeito. Compreender valores, culturas, realidades fazem com que o sujeito compreenda os processos de construção da sociedade, da cidadania e da democracia.

\begin{abstract}
O diálogo é a essência da emancipação humana, é sempre uma relação de iguais midiatizados pelo mundo. Mas, se dizer a palavra verdadeira, que é trabalho, que é práxis, é transformar o mundo, dizer a palavra não é privilégio de alguns homens, mas direito de todos os homens. Precisamente por isto, ninguém pode dizer a palavra verdadeira sozinho, ou dizê-la para os outros, num ato de prescrição, com o qual rouba a palavra aos demais. (FREIRE, 1987, p.78).
\end{abstract}

Dialogar requer esforço, atenção e dedicação do professor, do educador social. É um canal de exploração de percepções, pensamentos e novas perspectivas. Diálogo é também prevenção, é uma atitude responsável e humanizadora: ele auxilia na compreensão de quem é o ser humano, de como se desenvolve, atribuindo dessa maneira, conhecimento sobre seus comportamentos (LIMA, 2017a). Desse modo, Freire (1987, p. 06) reitera que "o diálogo fenomeniza e historiciza a essencial intersubjetividade humana, ela é relacional, nele, ninguém tem iniciativa absoluta. Os dialogantes "admiram" um mesmo mundo; afastam-se dele e com ele coincidem; nele põem-se e opõem-se".

Por meio do diálogo, a prevenção é pautada na construção e criação de vínculos afetivos, tanto familiares, quanto comunitários, que observam as situações de risco e de vulnerabilidade de um sujeito, oportunizando que não ocorram danos e, sim, a meIhoria da qualidade de vida por meio de uma relação pautada na segurança e na confiança entre educador e educando. Assim, só haverá possibilidades de aprendizagem à medida que a liberdade 
for construída ao lado da ética, do respeito, ao invés da obediência e do medo (FREIRE, 2000). Essa postura reforça a reflexão em que, à medida que se expressa o pensamento sobre a maneira de assimilar a constituição das problemáticas e da maneira com que se interage na sociedade, o autoritarismo não tem espaço.

\section{Considerações Finais}

Este estudo buscou valorizar a educação como um dos alicerces para se construir e se efetivar a justiça social em prol daqueles que estão a margem e sofrem com as desigualdades e vulnerabilidades sociais. Embora as pesquisas na área sejam recentes, elas trazem reflexões sobre a importância da educação no que concerne a superação de tais problemáticas. As obras de Freire e de outros autores que estudam sobre a educação e a justiça social inspiram demandas inovadoras, no que diz respeito à emancipação do sujeito por meio de uma transformação social, que acontece pelo ato de educar. A educação discutida neste artigo é voltada para a vida, para a paz, para a inclusão social, para a democracia e solidariedade e, portanto, é uma educação comprometida com o cuidado, com o coletivo e com liberdade. Compreende-se que a educação está intimamente ligada aos direitos humanos fundamentais, bem como a ética e a justiça social. Borges (2015, p. 37407) ressalta que a ética e a educação em diálogo, "tornam-se portadoras do arraigamento, da cultura dos direitos humanos e da justiça social. Por isso, a grande importância das instituições de ensino de todos os níveis para que a bandeira dos direitos humanos continue levantada".

Essas considerações acerca de uma educação transformadora a partir da realidade do sujeito podem contribuir efetivamente 
em ações impactantes em meio àqueles que estão imersos em situações de desigualdades e vulnerabilidades sociais, uma vez que a transformação acontece a partir da práxis, advinda da família, do próprio contexto social e de convivência, bem como da consciência e da formação cidadã. A educação é a via para a transformação do sujeito, para a interação social e a busca da humanização e, juntamente com ela, a educação preventiva integral, possibilita auxiliar o sujeito para a superação das suas necessidades. Neste sentido, pode-se afirmar a educação transformadora.

A educação, sendo a via de oportunidade do estabelecimento da justiça social, cria a conexão com seus protagonistas. Educadores e educandos estão em constante processo de aprendizagem, interação e humanização, abrindo o local para diferentes possibilidades. Essas oportunidades de aprendizagem auxiliam na construção da garantia dos direitos fundamentais, tais como as leis que asseguram o exercício da cidadania e da vida em coletividade. Como exemplo, há as discussões sobre a infância e adolescência que se fortaleceram e com isso, com base na Constituição Federal de 1988, surgiu o Estatuto da Criança e do Adolescente, em 13 de julho de 1990, assegurando direitos fundamentais a todas as crianças e adolescentes (exigibilidade).

A partir do Estatuto da Criança e do Adolescente, criaram-se as Redes de Proteção, a fim de proporcionar às crianças e adolescentes atendimentos integrais em todas as áreas: saúde, educação, assistência social, segurança, enquanto direitos, ou em qualquer outra necessidade básica para o seu crescimento sadio. Por trás de todo esse processo de garantia de direitos, a educação auxilia na promoção da justiça social, à medida que atua na construção da política e da ética na igualdade dos direitos, bem como da solidariedade do coletivo. 
Refletindo sobre os aspectos que culminam nas vulnerabilidades sociais, destaca-se que as violências, o capitalismo, as desigualdades sociais, precisam ser trabalhadas e exploradas em seus contextos, analisando quais são as suas origens e suas possíveis ferramentas de superação. Considerando a problemática envolvendo o mau emprego das tecnologias e seus impactos da vida humana, faz-se necessário reforçar que conhecimento seja expandido, que ocorra a educação científica e tecnológica de qualidade, que leve à real mudança social. Para isso, englobando uma visão crítica à respeito da tecnologia, ciência e sociedade, precisa-se provocar políticas públicas para suscitar esses avanços, de maneira que os cidadãos possam tornar-se livres da escravidão tecnológica e passem a viver menos superficialmente e ficticiamente.

É importante que os estudos científico-tecnológicos avancem a favor da humanidade, na perspectiva de bem-estar aos sujeitos e não para a sua devastação em prol de um fator econômico. Na compreensão de que existem jogos manipuladores dos grupos dominantes contra as classes menos favorecidas, não se deve deixar que a tecnologia atue única e exclusivamente para as tarefas do sistema econômico, político, religioso e moral. Trata-se de responsabilidade social e coletiva (SILVEIRA; BAZZO, 2005).

Com a reflexão acerca da ação educativa e da relação entre educador e educandos, tanto a Pedagogia escolar, quanto a Pedagogia Social poderão auxiliar na construção de sujeitos autônomos e democráticos. Poderão oportunizar no seu desenvolvimento humano, no reconhecimento de seus direitos e, no estímulo do diálogo e da interação social. Seres livres e pensantes poderão conscientizar-se de seus contextos culturais, políticos, econômicos e sociais e passar a compreender suas realidades vulneráveis, de perigo para sua evolução. Desse modo, compreendendo suas realidades, poderá se fortalecer para a construção do seu eu e do 
A Educação e a Justiça Social na Superação das Desigualdades Sociais Michelle Popenga Geraim Monteiro • Tatiane Delurdes de Lima-Berton, et al...

coletivo em que está envolvido. Será capaz de transformar sua realidade, de oportunizar espaços tolerantes, resilientes, corresponsáveis e com uma educação comprometida com a justiça social, a ética e a cidadania. Tornar seres humanos mais humanos.

\title{
Referências Bibliográficas
}

\author{
abramovay, Miriam; lima, Fabiano; VARElla, Santiago. Percepções \\ DOS ALUNOS SOBRE AS REPERCUSSÕES DA VIOLÊNCIA NOS ESTUDOS E NA INTERAÇÃO \\ SOCIAL NA ESCOLA. In: ABRAMOVAY, Miriam (ORg.). Escola e VIOlÊnCIA.
} BRASÍLIA: UNESCO, UCB, P. 89-117, 2003.

ASINELLI-LUZ, ARACI. VISÃo EDUCACIONAL dAS dROGAS: ORIENTAÇÃO PARA OS PAIS E PROFESSORES. In: ANDREOLI, CleVERSON V.; TORRES, PATríCIA LUPION. (Org.). Complexidade: redes e conexões do ser sustentável. Curitiba: SENAR - PARANÁ, P. 377 - 397, 2014.

Benatto, Maristela Elisabete Cosmo. A vulnerabilidade social da escola PÚBLICA E A FORMAÇÃO DOS PROFESSORES DO $6^{\circ}$ ANO DO ENSINO FUNDAMENTAL. IN: PARANÁ. OS DESAFIOS DA ESCOLA PÚBLICA PARANAENSE NA PERSPECTIVA DO PROfessor PDE. Universidade Tecnológica Federal do Paraná. Curitiba, 2016. BORGES, Valdir. DiReitos Humanos, ÉtICA, eduCAÇÃo E JUSTIÇA SOCIAL NA ERA da globalização partir de Paulo Freire. In: EDUCERE - XII Congresso Nacional de Educação, 2015, Curitiba. Anais de Eventos. PuCPR, Curitiba, 2015. BRANDÃO, Juliana Mendanha; MAHFOUd, Mıguel; GIANORDOLI-NASCIMENTO, INGRID FARIA. DA INVULNERABILIDADE À RESILIÊNCIA: PERCURSO HISTÓRICO e atualidade do conceito. In: RIBEIRO, WÂnier; ROMERO, Emilio. (Orgs.). VULNERABILIDADE HUMANA E CONFLITOS SOCIAIS: POR UMA PSICOLOGIA SOCIAL compreensiva. São José dos Campos: Della Bídia, 2009. cap. 8, p. 189-205. 
A Educação e a Justiça Social na Superação das Desigualdades Sociais Michelle Popenga Geraim Monteiro • Tatiane Delurdes de Lima-Berton, et al...

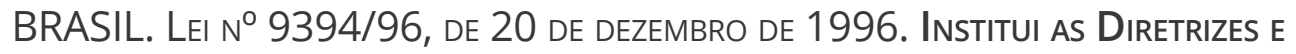
Bases da Educação Nacional. Diário Oficial, Brasília, Distrito Federal, 1996.

BRasil. Atlas da Vulnerabilidade Social nos Municípios Brasileiros. COSta, Marco Aurélio; MARGUti, Bárbara Oliveira (editores). Secretaria de Assuntos Estratégicos da PresidênCia da República. Instituto de Pesquisa Econômica Aplicada - IPEA. Brasília: IPEA, 2015.

Freire, Paulo. Pedagogia do oprimido. 23. ed. Rio de Janeiro: Paz e terra, 1987.

Freire, Paulo. Papel da educação na humanização. Revista da FAeEbA. Salvador-BA. v. 6 N. 7, P. 9-32, 1997.

FReire, Paulo. Pedagogia da Indignação: cartas pedagógicas e outros ESCRITOS. SÃo PaUlo: UNESP: 2000.

23

LiMA, Tatiane Delurdes de. O educador social e o pedagogo escolar na PREVENÇÃO do ABUSO DE DROGAS NA ADOLESCÊNCIA. 2017. 167f. DisSERTAÇÃO (Mestrado em Educação) - Setor de Educação, Universidade Federal do Paraná, Curitiba, 2017A.

MONTEiRo, Michelle Popenga Geraim. O bullying segundo a Percepção DOS ESTUDANTES DO $5^{\circ}$ ANO DO ENSINO FUNDAMENTAL. 2017, 148 F. DISSERtação (Mestrado em Educação) - Setor de Educação, Universidade Federal do Paraná, Curitiba, 2017b.

ROMERO, Emilio. Vulnerabilidade Humana e conflitos sociais: suas fonTES. In: ROMERO, EMILIO; RIBEIRO, WÂNIER (ORG). VULNERABILIDAdE HUMANA E CONFLITOS SOCIAIS: PARA UMA PSICOLOGIA SOCIAL COMPREENSIVA EXISTENCIAL. SÃO Paulo: Della Bídia, 2009.

SAlles filho, Nei Alberto. Cultura de paz, violência, conflitos e CONDIÇÃO DE POBREZA: APROXIMAÇÕES CONCEITUAIS E IMPLICAÇÕES SOCIAIS. IN: I 
